\title{
Domestic Animal Welfare at the Zoo: The Impact of an Animal Visitor Interaction Program on Chickens
}

\author{
Margaret Ramont, Maureen Leahy, \& Katherine A. Cronin*
}

Animal Welfare Science Program, Lincoln Park Zoo

*Corresponding author (Email: kcronin@lpzoo.org)

Citation - Ramont, M., Leahy, M. \& Cronin, K.A. (2021). Domestic animal welfare at the zoo: The impact of an animal visitor interaction program on chickens. Animal Behavior and Cognition, 8(1), 1-14. https://doi.org/10.26451/abc.08.01.01.2021

\begin{abstract}
Many modern zoos strive to create connections between guests and animals through animal visitor interaction (AVI) programs. However, there has been relatively little research into the effect of AVI programs on the welfare of program animals. Previous research has revealed three factors that may affect AVI program animal welfare: species differences, handling and transport, and the provision of choice and control. We assessed the effects of an AVI program designed with these factors in mind on the behavior of a flock $(N=16)$ of zoo-housed domestic chickens (Gallus gallus). Behavioral data were collected on program days and on non-program (control) days, and we considered the time leading up to the program, the program itself, and the time immediately following the program. When comparing flock behavior on program days to control days, we found no differences in behavioral indicators of welfare during the time leading up to the program and during the program. Rates of aggression, however, were significantly greater after the program had concluded compared to the same time period on matched control days, but still occurred infrequently. Additionally, we recorded the spatial location of each animal while the program occurred and found that the chickens did not spend significantly more or less time in the feeding zone as visitor participation increased, although there were individual differences within the flock. We conclude that the relatively small behavioral changes seen were not indicative of a change in welfare and consider those results in the context of the program design.
\end{abstract}

Keywords - Animal visitor interaction (AVI), Ambassador animal, Animal encounter, Gallus gallus, Behavior, Human-animal relationships

Many modern zoos serve as centers of conservation, education and research while striving to promote empathy for animals and encourage conservation action in visitors. While many potential methods exist to promote such connections (e.g., Ballantyne et al., 2011; Perdue et al., 2012; Young et al., 2018), close contact between visitors and animals remains popular. A recent study reported that $75 \%$ of websites associated with the World Association of Zoos and Aquariums advertised some sort of animal visitor interaction program (D'Cruze et al., 2019). The Association of Zoos and Aquariums (AZA) defines "ambassador animals" or "program animals," as "animal(s) whose role includes handling and/or training by staff or volunteers for interaction with the public and in support of institutional education and conservation goals" (Association of Zoos and Aquariums, 2015).

Considering the global popularity of ambassador animal programs, the welfare of ambassador animals has been the focus of relatively little research (Binding et al., 2020; de Mori et al., 2019). This may be due in part to the extraordinary range in species and in programmatic context that makes the scope of research questions quite broad and the opportunities for generalizations rare (Acaralp-Rehnberg, 2019; Saiyed et al., 2019). However, there are bodies of research that we can draw from to supplement our 
knowledge about the welfare of animals in zoo environments generally (reviewed in Ward \& Hosey, 2019) and in interactive contexts, specifically. Considering existing literature, we can identify at least three factors that may impact animal welfare in interaction programs.

First, there are probable species differences in the degree to which animal-visitor interaction programs will influence welfare. Animal behavior evolves within a social and ecological context; consequently, each species' response to their present environment will vary based on pressures historically faced by a species (Batson, 2004; Mason, 2010). Margulis et al. (2003) suggest that primates might be more sensitive to visitors because they have a shared evolutionary history resulting in some similar modes of communication with humans, whereas big cats may be less likely to be affected by human communicative signaling. Following a similar line of thinking, species that have undergone thousands of years of domestication alongside humans, on the other hand, may be differentially susceptible to welfare compromise induced by close proximity to humans compared to non-domesticated species. Certainly, selection associated with domestication has resulted in less anti-predator and aggressive behavior towards humans in general (Fraser \& Broom, 1990). Therefore, we could reason that domesticated species may fare better in ambassador animal programs. For example, one study demonstrated no profound impact on behavioral indicators of welfare in a petting zoo exhibit with goats, potbellied pigs, and llamas; however, all species' behavior changed as visitor density increased (Farrand et al., 2014). Another recent study reported no welfare compromise for domesticated guinea pigs in a zoobased program (Powell et al., 2020).

A second aspect of programmatic design that is likely to influence welfare is whether animals are handled or transported. Many interaction programs in zoos involve the handling and transport of animals from their primary enclosure to another location (D'Cruze et al., 2019). If we look beyond zoo-based research, we find that animal handling, generally speaking, has long been considered a source of potential stress and welfare compromise in laboratory animals (Balbcombe et al., 2004; Meany et al., 1996; Meijer et al., 2007; Núñez et al., 1996). Insights into the impact of on-grounds transportation on zoo animal welfare are just beginning to accumulate (e.g., Göttert et al., 2015; Tetzlaff et al., 2016), but generally speaking, transportation is associated with physiological or behavioral stress responses (e.g., CampbellPalmer \& Rosell, 2015; Fazio et al., 2019; Tonn et al., 2016; Volfová et al., 2019). In one study focused specifically on program animals in zoos, Baird et al. (2016) measured both behavioral and physiological indicators of welfare to investigate the effects of ambassador programming on three common program animals: armadillos (Lypeutes matacus, Chaetophractus vellerosus, Dasypus novemcinctus, Euphractus sexcinctus), red-tailed hawks (Buteo jamaicensis), and hedgehogs (Atelerix albiventris). In all three species, fecal glucocorticoid metabolite levels increased as the amount of handling and transport increased, as did stress-related behaviors in armadillos. The authors suggested that the animals did not habituate to handling and transport.

A third aspect of program design that is likely to influence animal welfare is the degree of control the animals are provided in their environment. The welfare benefit afforded by providing a level of autonomy to animals is seen across industries, with positive impacts shown for animals in companion (McMillan, 2020), farm (e.g., Jones \& Nicol, 1998; Špinka, 2019;), laboratory (Buchanan-Smith \& Badihi, 2012; Joffe et al., 1973; Mineka et al., 1986; Perdue et al., 2014), and zoo contexts (e.g., Brando \& Buchanan-Smith, 2018; Kurtycz et al., 2014; Morgan \& Tromborg, 2007; Ross, 2006; Veasey, 2017). For zoo-housed animals involved in programs, it appears that animals provided with the choice to "opt out" of the program experience better welfare outcomes than those without the option. For example, Anderson et al. (2002) found that goats and sheep in a petting zoo showed higher rates of guest-directed aggression when they did not have access to a retreat area that allowed them to separate from visitors. Additionally, in a recent study with African penguins (Spheniscus demersus, Saiyed et al., 2019), the authors reported no behavioral signs of welfare compromise in a program designed such that penguins could freely enter and leave a designated habitat area that seated guests.

Here, we evaluated a new AVI program at Lincoln Park Zoo, the "Feed-the-Chickens" program that was designed to support good welfare for the program animals considering the factors described above. Specifically, the program focused on a domesticated species, did not involve transportation or 
handling, and provided each animal the ability to choose to participate or abstain. We adopt the Five Domains model of animal welfare (Mellor \& Beausoleil, 2015), a framework that emphasizes the role that positive and negative subjective experiences have on an animal's welfare status. The subjective experiences (the mental domain) are influenced by the animal's nutrition, environment, health and behavior. Here, we measure behavior to make inferences about the underlying welfare state of the chickens.

We considered how positive and negative behavioral indicators of welfare change when the program is offered compared to when it is not. Specifically, we hypothesized that behaviors indicative of welfare, including aggressive and self-maintenance behaviors, would not significantly differ between program and non-program days. We were interested in aggressive behavior as a welfare indicator because increased distress or anxiety could manifest as increased intraspecific aggression, and because aggression sparked by the program could lead to psychological distress or physical discomfort in the group (Costa et al., 2012; Duncan \& Wood-Gush, 1971; Zimmerman et al., 2011). Self-maintenance behaviors were of interest as a welfare indicator given that a decrease in self-maintenance behaviors has been shown previously to be associated with a decline in welfare (Costa et al., 2012; Zimmerman et al., 2011). We also investigated changes in activity and feeding, expecting them to increase during the program due to the activity of visitors during the program, but not having specific welfare-related hypotheses. We considered each of these during the setup of the program, the program itself, and the time immediately following the program, to provide a better understanding of how expectation of the program, the program itself, or the completion of the program may be impacting welfare. Finally, we also measured the spatial location of the chickens during programs to determine how their proximity to the visitor area changed dependent upon the number of visitors present, providing a measure of the animals' comfort in the presence of visitors (e.g., Learmonth et al., 2018; Saiyed et al., 2019; Wark et al., 2019).

\section{Method}

\section{Subjects and Housing}

The domestic chicken flock at Lincoln Park Zoo's "Farm in the Zoo" consisted of one rooster and fifteen hens of several different breeds, ranging in age from 2-10 years old (Table 1). One female died during the study and her data are included for the dates she was present for space use analysis only due to a lack of sufficient behavioral observations. Subjects were housed in a fenced-in outdoor yard during the day (from approximately 8:00am to 4:00pm) and in a temperature-controlled coop overnight. The outdoor yard contained natural substrate of dirt and grass, and included a sand pit, mulch, a rope swing perch, horizontal logs, and two trees that provided shade (yard dimensions $5.9 \mathrm{~m} \mathrm{X} 9.1 \mathrm{~m}$ ). The indoor coop contained perches, nest boxes, and shavings (coop dimensions $2.6 \mathrm{~m}$ wide X $3.9 \mathrm{~m}$ long X $2 \mathrm{~m}$ high). Fortified chicken feed (Kent Extra Egg 16 brand) and fresh water were provided ad libitum in multiple locations in the yard.

\section{AVI Program}

The "Feed-the-Chickens" AVI program was offered multiple times per week from June-October 2019 between 11:30am-12:00pm. Volunteers greeted visitors as they arrived at the outer gate, explaining that they could place a single feeder stick through one of 7 feeder ports $(10 \mathrm{~cm} \mathrm{X} 10 \mathrm{~cm})$ in the fence (Figures 1, 2). Feeder sticks were comprised of a wooden dowel with a cup (diameter $3 \mathrm{~cm}$ ) attached to the end containing a small amount of chicken feed (the daily ad-libitum diet plus higher value items such as corn and oatmeal) into the cups (approximately $10 \mathrm{~g}$ ). Feeding happened on only one side of the chicken yard, and the flow of visitors was controlled by the volunteer staff, with a maximum of 15 visitors present in the feeding area at one time. At the end of the program, keepers or volunteers closed the feeder ports and the outer gate. 
Ramont et al. 4

Table 1

Sex, Breed, and Birth Year of the Chickens in this Study

\begin{tabular}{lccc}
\hline Name & Sex & Breed & Year of Birth \\
\hline Che & F & Buff-Laced Polish & 2018 \\
Tin & F & Buff-Laced Polish & 2018 \\
Pat & F & Buff-Laced Polish & 2018 \\
Cha & F & Buff-Laced Polish & 2018 \\
Tes & F & Dark Brahma & 2010 \\
Lay & F & Dark Brahma & 2010 \\
Cag & F & Golden-Laced Wyandotte & 2018 \\
Shi & F & Light Brahma & 2018 \\
Lav & F & Light Brahma & 2018 \\
Ven & F & Partridge Cochin & 2018 \\
Ser & F & Partridge Cochin & 2018 \\
Rog & F & Rhode Island red & 2017 \\
Sto & F & White Giant & 2017 \\
Lou* & F & White Giant & 2018 \\
The & F & White Giant & 2018 \\
Bea & M & Rhode Island red & 2017 \\
\hline
\end{tabular}

* indicates the subject that died partway through the study

Figure 1

Visitors Participating in Feed-the-Chickens Program

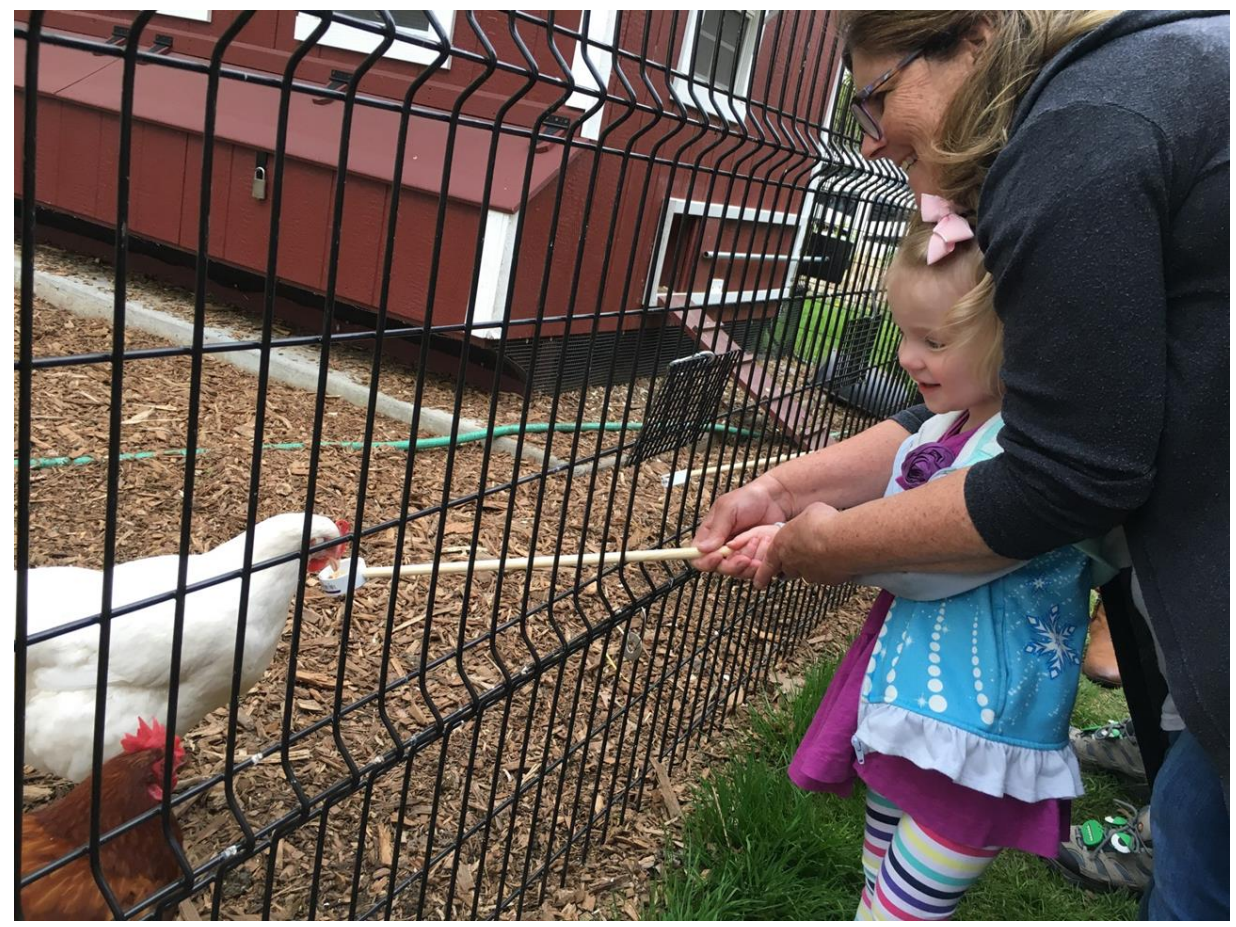


Figure 2

Map of Chicken Habitat

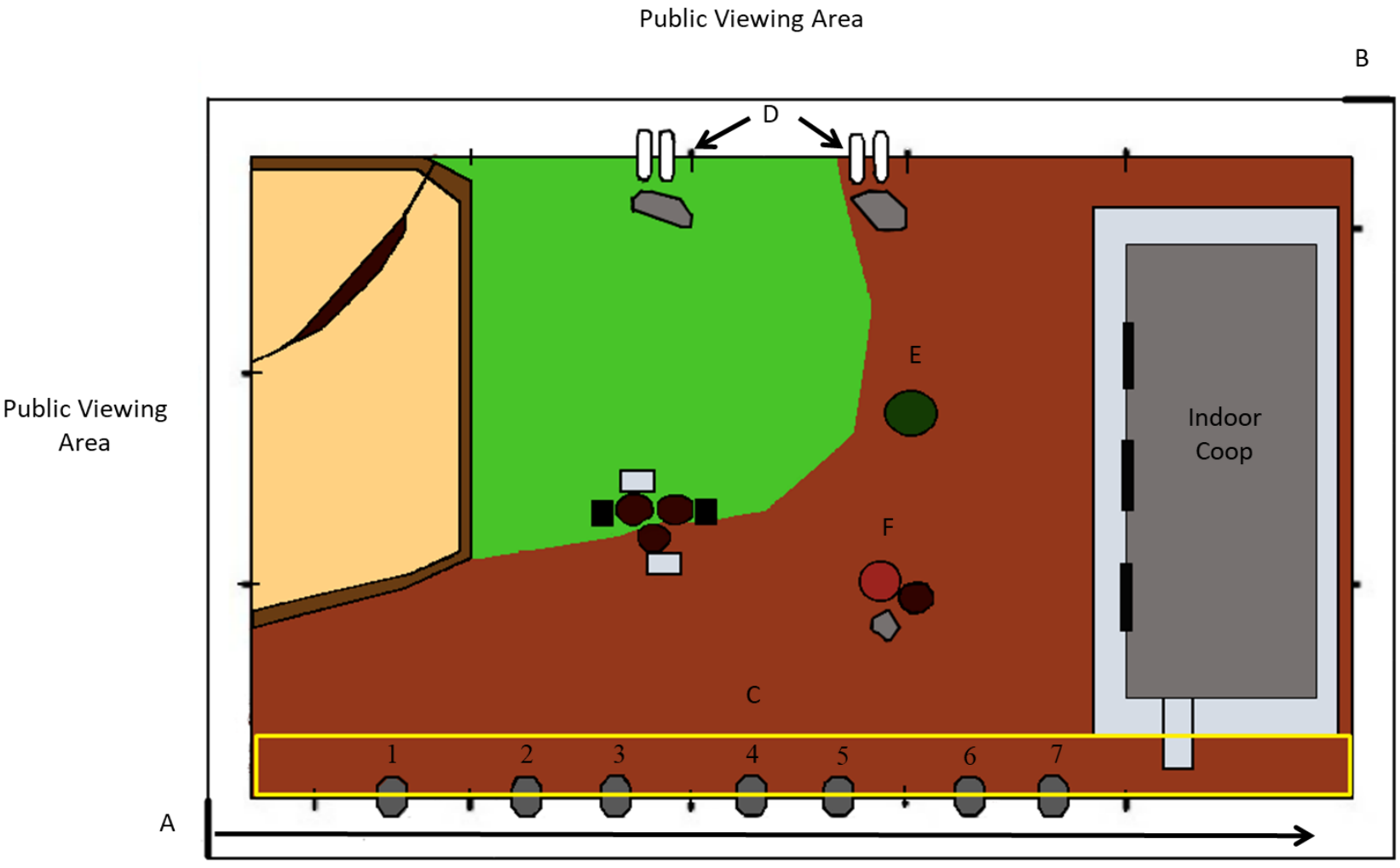

Note. A and B indicate the gates leading in and out of the visitor feeding area, and the arrow indicates the general direction of visitor movement. Visitors are instructed to enter through gate A and walk behind the coop building to exit at gate B; however, visitors occasionally exited from gate A. Numbers 1-7 indicate the feeder ports in the fence utilized by the program. The yellow box (indicated by $\mathrm{C}$ ) was defined as the feeding zone in the chicken enclosure. This zone measured approximately 3 chicken body lengths away from the feeding ports. D, E, and F mark the places where ad-libitum food and water were offered.

\section{Behavioral Data Collection}

Using the behavioral recording app ZooMonitor (Lincoln Park Zoo, 2020), an observer who had established $>85 \%$ inter-observer reliability with a second observer collected behavioral data on 45 weekdays from July-September 2019. Inter-observer reliability was calculated as percent agreement (Martin \& Bateson, 2007) using the ZooMonitor reliability module, and was calculated over four sessions for interval behaviors (100\% agreement), location (within 30 pixels on 600 x 600 pixel map of habitat; $90 \%$ agreement), and visitor counts (95\% agreement). Data for this study were collected during three observation periods: program set-up (characterized by volunteers arriving, buckets of feed brought into proximity, feeding sticks in view, feeding ports opened), during program (visitors allowed access along fence line to feed through ports), and after program (starting when visitors were no longer allowed access and continuing for $15 \mathrm{~min}$ ) (Figure 3). On non-program days, data were collected from 11:00am to $12: 15 \mathrm{pm}$, as a matched control (de Waal \& Yoshihara, 1983). This approach controls for changes in behavior due to factors besides the program, such as time of day, and has been utilized successfully in similar studies assessing the impact of programs on zoo animal behavior (Jacobson et al., 2019; Saiyed et al., 2019). Each observation day, we conducted sequential 5-minute sessions of focal animal sampling, with the order of focals randomized. We recorded all-occurrence behaviors and behaviors occurring at 1min intervals following the ethogram shown in Table 2 . The ethogram was specific to this study but was 
informed by previous studies (e.g., Daigle \& Siegford, 2014; Nicol, 1987; Ventura et al., 2012; Zimmerman et al., 2011). We also used the spatial mapping feature of ZooMonitor to record the location of the focal within the outdoor yard at 1-min intervals (Wark et al., 2019). Finally, during program observation periods, we recorded the number of visitors present in the feeding area at 1-minute intervals. Data were collected over the course of 45 days, with 30 days of programs and 15 matched control days. As with previous studies evaluating AVI program animal welfare (e.g., Farrand et al., 2014; Saiyed et al., 2019) there were an unequal number of observations between program and non-program conditions; However, we do not expect this to systematically bias results in either direction.

\section{Figure 3}

Matched Control Study Design for Observational Data Collection, Represented as a Timeline

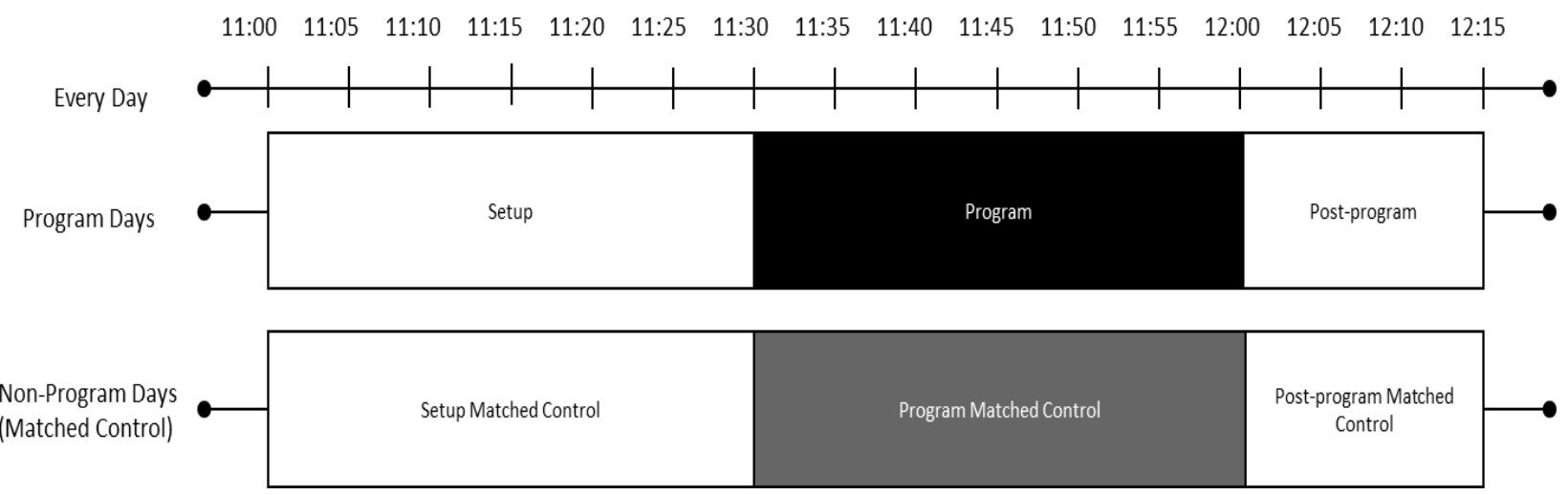

Note. Comparisons were made between program days and non-program days only, allowing for control of time of day in the study design.

\section{Statistical Analysis}

To test whether the program was associated with changes in behavior, we compared behavior on days that the program was offered with the same time on matched-control days using Wilcoxon rank sum tests. To minimize the possibility of Type II errors associated with multiple comparisons, we applied the Benjamani-Hotchberg correction that considers p-values sequentially by order of magnitude (Benjamini \& Hochberg, 1995). We applied the correction within program observation periods. To test whether the chickens' location within the yard was related to the number of visitors participating, we created a mixed effects logistic regression model with a binomial distribution. We transformed chicken location to a dichotomous outcome variable indicating whether the focal chicken was inside or outside of the feeding zone (Figure 2). Upon visual inspection of residual plots, we did not find any obvious deviations from homoscedasticity or normality. The number of visitors participating was included in the model as a fixed effect, and the observation session and focal were included as random effects. We obtained $p$-values through likelihood ratio tests of the full model against the null model with visitor number removed and considered AIC values. All analyses were conducted in R (Version 3.6.1; R Core Team, 2019), using base $\mathrm{R}$ and the package lme4 (Bates et al., 2015). 
Table 2

Ethogram

\begin{tabular}{|c|c|c|}
\hline Category & Behavior & Definition \\
\hline \multirow[t]{4}{*}{ Activity } & Digging/scratching & Animal is using their body in repetitive manner to excavate substrate with feet. \\
\hline & Ground pecking & $\begin{array}{l}\text { Animal is working to acquire a food item; pecking at the ground or substrate in } \\
\text { apparent attempt to find food. }\end{array}$ \\
\hline & Running & Animal is running through exhibit at least a distance greater than one body's length. \\
\hline & Walking & Animal is walking through exhibit at least a distance greater than one body's length. \\
\hline \multirow[t]{8}{*}{ Self-maintenance } & Dust bathing & Animal rolls in dry, loose dirt or sand. \\
\hline & Feather ruffling & Stretching neck, raising ruff and ruffling feathers and body. \\
\hline & Head flicking & Short, vigorous shaking of the head. \\
\hline & Head scratching & Leg brought upwards and forwards, under the wing, to scratch the lowered head. \\
\hline & Preening & $\begin{array}{l}\text { Animal may be sitting or standing and uses beak to manipulate, rearrange, pull, or } \\
\text { clean body feathers on self. }\end{array}$ \\
\hline & Stretching & Unilateral backward and downward movement of wings and leg together. \\
\hline & Wing flap & $\begin{array}{l}\text { Bilateral movement of the wings, including wing raising, without moving one body } \\
\text { length off the ground in any direction. }\end{array}$ \\
\hline & Yawning & Animal opens mouth widely while inhaling air. \\
\hline \multirow[t]{4}{*}{ Aggression } & Chase & Animal aggressively pursues another individual. \\
\hline & Leap & $\begin{array}{l}\text { Two birds face each other; one or both jump within two body lengths without } \\
\text { extending legs towards other bird. }\end{array}$ \\
\hline & Peck & Animal moves head and uses beak to touch a conspecific in a rapid manner. \\
\hline & Standoff & Two birds facing each other with heads at same level for at least 2 seconds. \\
\hline \multirow[t]{2}{*}{ Feeding } & Exhibit feeder & $\begin{array}{l}\text { Animal is ingesting food items from the exhibit feeders or manipulating a food item } \\
\text { for the purpose of feeding. }\end{array}$ \\
\hline & Program feeding & $\begin{array}{l}\text { Animal is ingesting food items from the visitors' feed sticks, or food items fallen } \\
\text { from feed sticks. }\end{array}$ \\
\hline
\end{tabular}




\section{Results}

We obtained 1145 min of behavioral observation on program days and 684 min of observation on matched-control days. Focal observation time per subject ranged from 99 to $136 \mathrm{~min}$ (excluding the female who died during the study who was the subject of 29 min of observation).

\section{Behavior During Program Setup}

We compared behavior when the volunteers and keepers were setting up for the program with nearly the same time of day on matched-control days to determine whether anticipation of the program, or cues the program was about to begin, affected behavior. We obtained $103 \mathrm{~min}$ of behavioral observation on program days and 245 min of observation on matched-control days. The sample size, medians, IQR, and results of the Wilcoxon rank sum tests are provided in Table 3. Aggression, self-maintenance behavior, activity, and feeding were not significantly different during set-up and matched controls.

Table 3

Results of Comparisons of Behavior During Program Setup and Matched Control Periods

\begin{tabular}{|c|c|c|c|c|c|c|c|}
\hline Behavior & Condition & $N$ & $M d n$ & IQR & Wilcoxon W & $\begin{array}{l}\begin{array}{c}\text { Original } p- \\
\text { value }\end{array} \\
\end{array}$ & $\begin{array}{c}\text { Corrected } p \text { - } \\
\text { value }\end{array}$ \\
\hline \multirow[t]{2}{*}{ Aggression } & Matched Control & 15 & 0.004 & 0.004 & 52.5 & 619 & 699 \\
\hline & Program set up & 15 & 0.019 & 0.032 & & & \\
\hline \multirow[t]{2}{*}{$\begin{array}{l}\text { Self- } \\
\text { Maintenance }\end{array}$} & Matched Control & 15 & 0.090 & 0.037 & 54 & 699 & 699 \\
\hline & Program set up & 15 & 0.091 & 0.052 & & & \\
\hline \multirow[t]{2}{*}{ Activity } & Matched Control & 15 & 0.333 & 0.255 & 29 & .041 & .166 \\
\hline & Program set up & 15 & 0.600 & 0.313 & & & \\
\hline \multirow[t]{2}{*}{ Feeding } & Matched Control & 15 & 0.056 & 0.054 & 84 & .118 & .235 \\
\hline & Program set up & 15 & 0.000 & 0.077 & & & \\
\hline
\end{tabular}

\section{Behavior During the Program}

We compared behavior during the program with the same time on matched-control days to determine how the presence of visitors in close proximity to the chickens and offering feeding sticks, affected behavior. We obtained 621 min of behavioral observation on program days and 294 min of observation on matched-control days. The sample size, medians, IQR, and results of the Wilcoxon rank sum tests for the four behavioral categories (aggression, self-maintenance, activity, and feeding) are provided in Table 4. Considering the corrected $p$-values, there were no significant differences in any behavioral category between times when the program was offered and the same time on matched control days when the program was not offered. Although the corrected $p$-value for feeding behavior did not indicate a significant increase in the time spent feeding during programs, we did find that chickens fed significantly more often from visitors than from exhibit feeders during programs (Median proportion of scans feeding from visitors $=0.184, \mathrm{IQR}=0.112$; Median proportion of scans feeding from exhibit feeders $=0.029, \mathrm{IQR}=0.069, N=15, \mathrm{~W}=51.5, p=.012$ ). The results of the mixed effects logistic regression indicated that the number of visitors participating in the program did not significantly predict 
the presence of chickens in the feeding zone (full-null model comparison, $\chi^{2}(\mathrm{df}=1,2)=1.779, p=.182$ ). Comparing AIC values also indicated that the full model containing visitor number did not improve model fit (AIC full model $=437.51$, AIC null model $=437.73$ ). However, additional exploration revealed considerable variation between individual chickens in time spent in the feeding zone (Figure 4).

Table 4

Results of Comparisons of Behavior During Programs and Matched Control Periods

\begin{tabular}{|c|c|c|c|c|c|c|c|}
\hline Behavior & Condition & $N$ & $M d n$ & IQR & Wilcoxon W & $\begin{array}{c}\text { Original } p \text { - } \\
\text { value }\end{array}$ & $\begin{array}{c}\text { Corrected } p \text { - } \\
\text { value }\end{array}$ \\
\hline \multirow{2}{*}{ Aggression } & Matched Control & 15 & 0.004 & 0.008 & 63 & .0416 & .1041 \\
\hline & Program & 15 & 0.011 & 0.011 & & & \\
\hline \multirow{2}{*}{ Self-Maintenance } & Matched Control & 15 & 0.078 & 0.042 & 152 & .1057 & .1762 \\
\hline & Program & 15 & 0.055 & 0.032 & & & \\
\hline \multirow{2}{*}{ Activity } & Matched Control & 15 & 0.400 & 0.300 & 125 & .6185 & .5186 \\
\hline & Program & 15 & 0.400 & 0.159 & & & \\
\hline \multirow{2}{*}{ Feeding } & Matched Control & 15 & 0.032 & 0.167 & 53 & .0140 & .0701 \\
\hline & Program & 15 & 0.200 & 0.137 & & & \\
\hline \multirow[t]{2}{*}{ Feeding Zone } & Matched Control & 15 & 0.111 & 0.277 & 96.5 & .5186 & .5186 \\
\hline & Program & 15 & 0.143 & 0.134 & & & \\
\hline
\end{tabular}

Figure 4

Individual Differences in the Percent of scans During which Chickens were Located in the Feeding Zone (the area Closest to Program Participants) During the Feeding Program

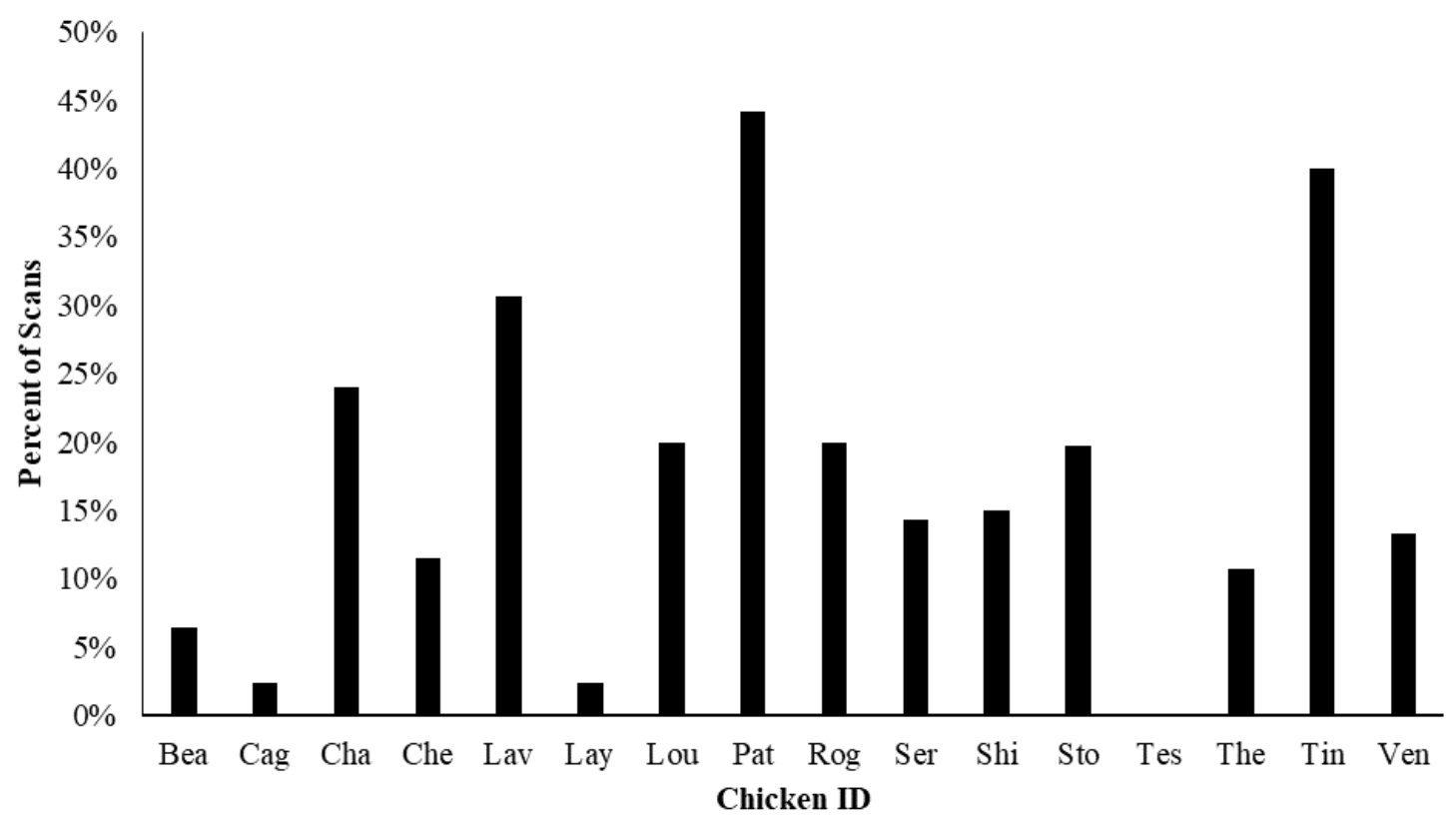




\section{Behavior After the Program}

We recorded behavior for $15 \mathrm{~min}$ following the program and compared it to the same time on matched-control days to determine how the termination of the program affected behavior. We obtained $420 \mathrm{~min}$ of behavioral observation following the program and $145 \mathrm{~min}$ of observation on matched-control days. The sample size, medians, IQR, and results of the Wilcoxon rank sum tests are provided in Table 5. Activity, feeding, and self-maintenance behaviors did not differ significantly; however, the frequency of aggressive behavior increased significantly in the post-program session compared to the same time period on matched-control days.

Table 5

Results of Comparisons of Behavior after the Program and Matched Control Periods

\begin{tabular}{|c|c|c|c|c|c|c|c|}
\hline Behavior & Condition & $N$ & Mdn & IQR & Wilcoxon W & Original $p$-value & Corrected $p$-value \\
\hline \multirow{2}{*}{ Aggression } & Baseline & 15 & 0.000 & 0.001 & \multirow{2}{*}{18.5} & \multirow{2}{*}{.001} & \multirow{2}{*}{.006} \\
\hline & Program & 15 & 0.009 & 0.005 & & & \\
\hline \multirow{2}{*}{ Self-Maintenance } & Baseline & 15 & 0.080 & 0.065 & \multirow{2}{*}{117} & \multirow{2}{*}{.868} & \multirow{2}{*}{.868} \\
\hline & Program & 15 & 0.068 & 0.028 & & & \\
\hline \multirow{2}{*}{ Activity } & Baseline & 15 & 0.357 & 0.259 & \multirow{2}{*}{121} & \multirow{2}{*}{.740} & \multirow{2}{*}{.868} \\
\hline & Program & 15 & 0.325 & 0.177 & & & \\
\hline \multirow{2}{*}{ Feeding } & Baseline & 15 & 0.000 & 0.067 & \multirow{2}{*}{96} & \multirow{2}{*}{.478} & \multirow{2}{*}{.868} \\
\hline & Program & 15 & 0.033 & 0.127 & & & \\
\hline
\end{tabular}

\section{Discussion}

We focused this research on the welfare implications of a new ambassador animal program that involved a domestic species, did not involve handling or transport, and provided the animals the choice of whether or not to participate. These program characteristics were specifically chosen based on existing literature to set the stage for good animal welfare, and the goal of this study was to determine whether chickens exposed to the program showed any signs of welfare compromise. We were specifically interested in whether there would be any behavioral indicators of welfare change associated with the anticipation of this program, its execution, or its completion. Overall, we found very little behavioral change associated with offering the program, supporting the general conclusion that this program did not generate a compromise in chicken welfare.

We observed an increase in aggressive behavior following the completion of the program. This finding indicates that some aspect of the program completion may be inducing conflict or distress in the flock that can be minimized moving forward. Aggression is one of the most common welfare indicators used when evaluating the effects of animal encounter programs (Sherwen \& Hemsworth, 2019). However, it is important to note that overall levels of aggression were low even following programs, averaging 0.64 aggressive events per hour. Chasing and pecking were the two forms of aggressive behavior seen, and the rate observed here was far below what is typically reported in agricultural settings (e.g., Nicol et al., 1999; Shi et al., 2018). Regardless, this finding sparks inquiry into whether there are aspects of how the program is concluded that stimulate aggression in the flock. Two possibilities are the discontinued access to the supplementary, higher-valued food source (Banks et al., 1979) and the physical act of familiar keepers or volunteers approaching the feeding ports and closing them. Moving forward, we plan to informally experiment with different strategies for completing the program that include varying the quality of the food and dissociating the removal of the food source with the closing of the ports to determine what may be triggering this moderate increase in aggression. 
We also used spatial location to gain insight into the chickens' comfort with the program. Space use can be a useful indicator of animal comfort; animals tend to avoid areas that are unpleasant and spend time in areas in which they are comfortable (Wark et al., 2019). Specifically, we evaluated whether chickens avoided the area of their habitat closest to the visitors as visitor counts increased in those areas. Seeing such a pattern would suggest that chickens were uncomfortable with visitors; likewise, seeing an increase in time spent in that area as visitor numbers increased could indicate an attraction to greater numbers of visitors or to the food that they provide. For example, Learmonth et al. (2018) found that quokkas housed in a walk-through enclosure spent more time hidden from the path when visitors were present, suggesting that they were avoiding human contact and were at least moderately fearful of humans. Here, we found that the number of visitors did not provide any additional explanatory value to our model of chicken location. This finding indicates that the flock as a whole was neither averse to, nor drawn toward visitors participating in the program. By extension, this suggests a neutral effect of visitor presence (Hosey, 2008).

The increase in feeding behavior during programs was not significant; however, chickens preferred the food provided by the visitors over the food provided by the exhibit feeders during programs, suggesting that the visitor feed was attractive to at least some of the chickens. It is possible that there was a simultaneous attraction to visitor feed that masked a desire to avoid visitors, but this seems unlikely given that we did not see behavioral indicators of welfare compromise. However, future work could tease apart the potential conflicting influences of visitors themselves and the resources they provide to the animals during programs.

There is likely to be individual variation within species that are provided with the same type of programmatic experience (Nawroth et al., 2017; Stoinski et al., 2012). In another study of program animal behavior, Saiyed et al. (2019) found that African penguins that were scored as "bolder" in a temperament test were more likely to voluntarily participate in an encounter program, suggesting that all penguins were not equally comfortable in the voluntary, non-contact, non-transport program. We see a similar pattern of differential participation here, with a few individuals showing no motivation to approach visitors and engage in the program, and others spending nearly half their available time near feeding guests. Whether this individual variation reflects differing levels of comfort, interest, or socially constrained access remains to be determined. However, we can conclude that, as with previous studies of program animal comfort, individuals vary in their ability or motivation to participate, underscoring the importance of providing choice to the animals about whether or not to participate.

Given the minimal behavioral change associated with offering the program, we tentatively conclude that the program did not have any negative impact on animal welfare. There are some limitations to this study to note, however. First, the small sample size and conservative correction for multiple comparisons to protect against Type II error may have diminished our ability to detect some small, yet interesting differences in behavior. We also cannot determine which aspects of the program design - the domestic species chosen, the lack of physical contact, the lack of transport, or the voluntary nature - influenced the outcomes observed here. Both of these limitations could be overcome through systematic study involving multiple institutions. However, this study demonstrates how relying on existing animal welfare science gleaned from various industries can facilitate the development of a program that is unlikely to have a negative impact on animal welfare.

\section{Acknowledgements}

We thank the staff at Cosley Zoo for sharing this great program idea with us. We thank Mike Murray, Cassy Kutilek, and the Farm-in-the-Zoo Keepers for feedback on study design and logistical support, and Jason Wark and Natasha Wierzal for assistance with ethogram development and ZooMonitor. We thank Amy Anderson and the Volunteer Services Department for facilitating the program and working with us. We thank the Lincoln Park Zoo Learning Department for information and collaboration, and the Internships Matter Fund for financial support. 


\section{References}

Association of Zoos and Aquariums. (2015). AZA ambassador animal policy. https://www.aza.org/aza-ambassadoranimal-policy.

Acaralp-Rehnberg, L. K. (2019). Human-animal interaction in the modern zoo: Live animal encounter programs and associated effects on animal welfare [unpublished doctoral dissertation]. University of Melbourne.

Anderson, U. S., Benne, M., Bloomsmith, M. A., \& Maple, T. L. (2002). Retreat space and human visitor density moderate undesirable behavior in petting zoo animals. Journal of Applied Animal Welfare Science, 5(2), $125-137$.

Baird, B. A., Kuhar, C. W., Lukas, K. E., Amendolagine, L. A., Fuller, G. A., Nemet, J., Willis, M. A., \& Schook, M. W. (2016). Program animal welfare: Using behavioral and physiological measures to assess the wellbeing of animals used for education programs in zoos. Applied Animal Behaviour Science, 176, 150-162.

Balbcombe, J. P., Barnard, N. D., \& Sandusky, C. (2004). Laboratory routines cause animal stress. Contemporary Topics in Laboratory Animal Science 43(6), 42-51.

Ballantyne, R., Packer, J., \& Sutherland, L. A. (2011). Visitors' memories of wildlife tourism: Implications for the design of powerful interpretive experiences. Tourism Management, 32(4), 770-779.

Banks, E. M., Wood-Gush, D. G., Hughes, B. O., \& Mankovich, N. J. (1979). Social rank and priority of access to resources in domestic fowl. Behavioural Processes, 4(3), 197-209.

Bates, D., Mächler, M., Bolker, B., \& Walker, S. (2015). Fitting linear mixed-effects models using lme4. Journal of Statistical Software, 67(1), 1-48.

Bateson, P. (2004). The active role of behaviour in evolution. Biology and Philosophy, 19(2), 283-298.

Benjamini, Y., \& Hochberg, Y. (1995). Controlling the false discovery rate: A practical and powerful approach to multiple testing. Journal of the Royal Statistical Society: Series B (Methodological), 57(1), 289-300.

Binding, S., Farmer, H., Krusan, L., \& Cronin, K. A. (2020). The status of zoo and aquarium welfare research: Where are we, where to next? Journal of Zoo and Aquarium Research, 8(3), 166-174.

Brando, S., \& Buchanan-Smith, H. M. (2018). The 24/7 approach to promoting optimal welfare for captive wild animals. Behavioural Processes, 156, 83-95.

Buchanan-Smith, H. M., \& Badihi, I. (2012). The psychology of control: Effects of control over supplementary light on welfare of marmosets. Applied Animal Behaviour Science, 137(3-4), 166-174.

Campbell-Palmer, R., \& Rosell, F. (2015). Captive care and welfare considerations for beavers. Zoo Biology, 34(2), 101-109.

Costa, L. S., Pereira, D. F., Bueno, L. G. F., \& Pandorfi, H. (2012). Some aspects of chicken behavior and welfare. Brazilian Journal of Poultry Science, 14(3), 159-164.

D’Cruze, N., Khan, S., Carder, G., Megson, D., Coulthard, E., Norrey, J., \& Groves, G. (2019). A global review of animal-Visitor Interactions in modern zoos and aquariums and their implications for wild animal welfare. Animals, 9(6), 332.

Daigle, C. L., \& Siegford, J. M. (2014). When continuous observations just won't do: Developing accurate and efficient sampling strategies for the laying hen. Behavioural Processes, 103, 58-66.

de Mori, B., Ferrante, L., Florio, D., Macchi, E., Pollastri, I., \& Normando, S. (2019). A protocol for the ethical assessment of wild animal-visitor interactions (AVIP) evaluating animal welfare, education, and conservation outcomes. Animals, 9(8), 487.

de Waal, F. B., \& Yoshihara, D. (1983). Reconciliation and redirected affection in rhesus monkeys. Behaviour, 85(3), 224-241.

Duncan, I. J. H., \& Wood-Gush, D. G. M. (1971). Frustration and aggression in the domestic fowl. Animal Behaviour, 19(3), 500-504.

Farrand, A., Hosey, G., \& Buchanan-Smith, H. M. (2014). The visitor effect in petting zoo-housed animals: Aversive or enriching? Applied Animal Behaviour Science, 151, 117-127.

Fazio, J., Freeman, E. W., Bauer, E. B., \& Parsons, E. C. M. (2019). Evaluation of management in North American zoos to enhance breeding success of the fishing cat (Prionailurus viverrinus) ex situ population. Zoo Biology, 38(2), 189-199.

Fraser, A. F., \& Broom, D. M. (1990). Farm animal behaviour and welfare. CAB International.

Göttert, T., Grothmann, P., \& Zeller, U. (2015). Faecal corticosterone responses of black rhinos (Diceros bicornis) to a transfer between housing facilities within a zoo. Journal of Zoo and Aquarium Research, 3(1), 25-28.

Hosey, G. (2008). A preliminary model of human-animal relationships in the zoo. Applied Animal Behaviour Science, 109(2-4), 105-127. 
Jacobson, S. L., Kwiatt, A. C., Ross, S. R., \& Cronin, K. A. (2019). The effects of cognitive testing on the welfare of zoo-housed Japanese macaques (Macaca fuscata). Applied Animal Behaviour Science, 212, 90-97.

Joffe, J. M., Rawson, R. A., \& Mulick, J. A. (1973). Control of their environment reduces emotionality in rats. Science, 180(4093), 1383-1384.

Jones, R., \& Nicol, C. J. (1998). A note on the effect of control of the thermal environment on the well-being of growing pigs. Applied Animal Behaviour Science, 60(1), 1-9.

Kurtycz, L. M., Wagner, K. E., \& Ross, S. R. (2015). The choice to access outdoor areas affects the behavior of great apes. Journal of Applied Animal Welfare Science, 17(3), 185-197.

Learmonth, M. J., Sherwen, S., \& Hemsworth, P. H. (2018). The effects of zoo visitors on Quokka (Setonix brachyurus) avoidance behavior in a walk-through exhibit. Zoo Biology, 37(4), 223-228.

Lincoln Park Zoo (2020). ZooMonitor (version 3.2) [Mobile application software]. https://zoomonitor.org.

Margulis, S. W., Hoyos, C., \& Anderson, M. (2003). Effect of felid activity on zoo visitor interest. Zoo Biology, 22(6), 587-599.

Martin, P., \& Bateson, P. (2007). Measuring behaviour: An introductory guide. Cambridge University Press.

Mason, G. J. (2010). Species differences in responses to captivity: Stress, welfare and the comparative method. Trends in Ecology \& Evolution, 25(12), 713-721.

McMillan, F. D. (2020). The mental health and well-being benefits of personal control in animals. In F. D. McMillan (Ed.), Mental health and well-being in animals, $2^{\text {nd }}$ ed. (pp.67-81). CABI.

Meany, M. J., Diorio J., Francis D., Widdowson J., LaPlante P., Caldji, C., Seckl, J. R., \& Plotsky, P. M. (1996). Early environmental regulation of forebrain glucocorticoid receptor gene expression: Implications for adrenocortical responses to stress. Developmental Neuroscience, 18, 49-72.

Meijer, M. K., Sommer, R., Spruijt, B. M., van Zutphen, L. F., \& Baumans,V. (2007). Influence of environmental enrichment and handling on the acute stress response in individually housed mice. Laboratory Animals, 41, 161-173.

Mellor, D. J., \& Beausoleil, N. J. (2015). Extending the 'Five Domains' model for animal welfare assessment to incorporate positive welfare states. Animal Welfare 24(3), 241-253.

Mineka, S., Gunnar, M., \& Champoux, M. (1986). Control and early socioemotional development: Infant rhesus monkeys reared in controllable versus uncontrollable environments. Child Development, 57(5), 1241-1256.

Morgan, K. N., \& Tromborg, C. T. (2007). Sources of stress in captivity. Applied Animal Behaviour Science, 102(34), 262-302.

Nawroth, C., Prentice, P. M., \& McElligott, A. G. (2017). Individual personality differences in goats predict their performance in visual learning and non-associative cognitive tasks. Behavioural Processes, 134, 43-53.

Nicol, C. J. (1987). Effect of cage height and area on the behaviour of hens housed in battery cages. British Poultry Science, 28(2), 327-335.

Nicol, C. J., Gregory, N. G., Knowles, T. G., Parkman, I. D., \& Wilkins, L. J. (1999). Differential effects of increased stocking density, mediated by increased flock size, on feather pecking and aggression in laying hens. Applied Animal Behaviour Science, 65(2), 137-152.

Núñez, J. F., Ferré, P., Escorihuela, R. M., Tobeña, A., \& Fernández-Teruel, A. (1996). Effects of postnatal handling of rats on emotional, HPA-axis, and prolactin reactivity to novelty and conflict. Physiology \& Behavior, 60(5), 1355-1359.

Perdue, B. M., Evans, T. A., Washburn, D. A., Rumbaugh, D. M., \& Beran, M. J. (2014). Do monkeys choose to choose? Learning \& Behavior, 42(2), 164-175.

Perdue, B. M., Stoinski, T. S., \& Maple, T. L. (2012). Using technology to educate zoo visitors about conservation. Visitor Studies, 15(1), 16-27.

Powell, D. M., Kozlowski, C. P., Clark, J., Seyfried, A., Baskir, E., \& Franklin, A. D. (2020). Physical and physiological indicators of welfare in guinea pigs (Cavia porcellus) serving as ambassador animals. Animals, 10(5), 815.

R Core Team. (2019). A language and environment for statistical computing. Vienna, Austria. https://www.Rproject.org.

Ross, S. R. (2006). Issues of choice and control in the behaviour of a pair of captive polar bears (Ursus maritimus). Behavioural Processes, 73(1), 117-120.

Saiyed, S. T., Hopper, L. M., \& Cronin, K. A. (2019). Evaluating the behavior and temperament of African penguins in a non-contact animal encounter program. Animals, 9(6), 326.

Sherwen, S. L., \& Hemsworth, P. H. (2019). The visitor effect on zoo animals: Implications and opportunities for zoo animal welfare. Animals, 9(6), 366. 
Shi, H. P., Zheng, W. C., Tu, J., \& Li, B. M. (2018). Reducing feather pecking and cloacal cannibalism by providing layer breeders with nest boxes in colony cages for natural mating. International Journal of Agricultural and Biological Engineering, 11(6), 27-32.

Špinka, M. (2019). Animal agency, animal awareness and animal welfare. Animal Welfare, 28(1), 11-20.

Stoinski, T. S., Jaicks, H. F., \& Drayton, L. A. (2012). Visitor effects on the behavior of captive western lowland gorillas: The importance of individual differences in examining welfare. Zoo Biology, 31(5), 586-599.

Tetzlaff, S. J., Tetzlaff, K. E., \& Connors, R. J. (2016). Evaluation of thermal regimes for transported ambassador ectotherms: One size does not fit all. Zoo Biology, 35(4), 339-345.

Tonn, N., Novais, S. C., Silva, C. S., Morais, H. A., Correia, J. P., \& Lemos, M. F. (2016). Stress responses of the sea cucumber Holothuria forskali during aquaculture handling and transportation. Marine Biology Research, 12(9), 948-957.

Veasey, J. S. (2017). In pursuit of peak animal welfare: The need to prioritize the meaningful over the measurable. Zoo Biology, 36(6), 413-425.

Ventura, B. A., Siewerdt, F., \& Estevez, I. (2012). Access to barrier perches improves behavior repertoire in broilers. PLOS One, 7(1). e29826.

Volfová, M., Machovcová, Z., Schwarzenberger, F., Voslářová, E., Bedáňová, I., \& Večerek, V. (2019). The effects of transport stress on the behaviour and adrenocortical activity of the black-and-white ruffed lemur (Varecia variegata). Acta Veterinaria Brno, 88(1), 85-92.

Ward, S. J., \& Hosey, G. (2019). The need for a convergence of agricultural/laboratory and zoo-based approaches to animal welfare. Journal of Applied Animal Welfare Science, 23(4), 484-492.

Wark, J. D., Cronin, K. A., Niemann, T., Shender, M. A., Horrigan, A., Kao, A., \& Ross, M. R. (2019). Monitoring the behavior and habitat use of animals to enhance welfare using the ZooMonitor app. Animal Behavior and Cognition, 6(3), 158-167.

Young, A., Khalil, K. A., \& Wharton, J. (2018). Empathy for animals: A review of the existing literature. Curator: The Museum Journal, 61(2), 327-343.

Zimmerman, P. H., Buijs, S. A. F., Bolhuis, J. E., \& Keeling, L. J. (2011). Behaviour of domestic fowl in anticipation of positive and negative stimuli. Animal Behaviour, 81(3), 569-577. 